American Journal of Biochemistry and Biotechnology 6 (3): 148-154, 2010

ISSN 1553-3468

(C) 2010 Science Publications

\title{
Expression, Purification and Activity Assay of the Recombinant Protein of Catechol-O-Methyltransferase from Chinese White Shrimp (Fenneropenaeus chinensis)
}

\author{
${ }^{1}$ Dian-Xiang Li, ${ }^{2,3}$ Xin-Jun Du, ${ }^{2}$ Xiao-Fan Zhao and ${ }^{2}$ Jin-Xing Wang \\ ${ }^{1}$ School of Medicine and Life Science, University of Jinan, Jinan, 250022, China \\ ${ }^{2}$ School of Life Sciences, Shandong University, Jinan, Shandong, 250100, PR, China \\ ${ }^{3}$ Key Laboratory of Food Nutrition and Safety, Ministry of Education, \\ Tianjin University of Science and Technology, Tianjin, 300457, China
}

\begin{abstract}
Problem statement: We have previously cloned a gene of Chinese white shrimp Catechol O-Methyltransferase (designated Fc-COMT) and characterized the gene expression pattern. In this study, expression and purification as well as activity assay of the recombinant Fc-COMT was further conducted. Approach: Using pET-30a (+) as a prokaryotic expression vector, the recombinant FcCOMT was expressed in the supernatant of Escherichia coli lysate and easily purified by His-Bind resin chromatography. SDS-PAGE analysis showed that the molecular mass of recombinant Fc-COMT was approximately 30,000 Da, in good agreement with the software-predicted molecular weight. The enzymatic activity of recombinant Fc-COMT was tested using Dihydroxybenzoic Acid (DHBAc) as a substrate. Results: The methyl products of DHBAc, Vanillic Acid (VA) and Isovanillic Acid (IVA), were detected in the enzymatic reaction mixture with recombinant Fc-COMT by High Performance Liquid Chromatography-Mass Spectrometry (HPLC-MS). Conclusion: The recombinant Fc-COMT has catalytic activity of transferring methyl group from S-Adenosyl-L-Methionine (SAM) to the 3' hydroxyl or 4' hydroxyl group of benzyl ring of DHBAc.
\end{abstract}

Key words: Fenneropenaeus chinensis, recombinant Fc-COMT, VA, HPLC-MS

\section{INTRODUCTION}

Catechol-O-Methyltransferase (COMT, E.C.2.1.1.6.) is one of O-methyltransferases that catalyse the formation of methoxylated products by transferring one methyl group from S-adenosyl-L-methionine to the hydroxyl group of molecules containing a catechol moiety in the presence of $\mathrm{Mg}^{2+}$ (Axelrod and Tomchick, 1958). Thus, COMT can inactivate catecholamines and other catechol-type compounds including many catecholcontaining xenobiotics and drugs (Mannisto et al., 1992; Bonifacio et al., 2002).

Researchers have achieved a lot in COMT studies including gene cloning (Bertocci et al., 1991), gene expressions (Matsumoto et al., 2003; Tilgmann and Ulmanen, 1996), gene functions (Chen et al., 2004), enzyme kinetics (Bonifacio et al., 2002) and enzyme inhibitors (Mannisto et al., 1992), most of which were from mammal COMTs, especially from human COMT. For example, it has been found that the sequence variations of the COMT gene and the COMT activity level were associated with cancer risk and schizophrenia susceptibility in human (Karayiorgou et al., 1998; Cheng et al., 2005). COMT inhibitors have also been developed as adjuvant drugs in the treatment of Parkinson's disease (Schrag, 2005). So, COMT is involved in the studies of pharmacology and etiology for some diseases.

Since human COMT was reported in 1958, COMTs have been found in invertebrates (Guldberg and Marsden, 1975). However, no crustacean COMT, except for Chinese white shrimp ( $F$. chinensis) COMT (Fc-COMT), has yet been reported. We have previously cloned a Fc-COMT gene and characterized the gene expression pattern ( $\mathrm{Li}$ et al., 2006). The sequence data of the Fc-COMT gene has also been submitted to the GenBank databases under accession number DQ091255. In order to further analyze the enzymatic activity of the Fc-COMT, this study was conducted.

COMT activity may be estimated from the reaction products that were made by enzymatic O-methylation of substrates after termination of the enzymatic reaction (Axelrod and Tomchick, 1958). It was known that the substrates of COMT were various, some of which were

Corresponding Author: Jin-Xing Wang, School of Life Sciences, Shandong University, Jinan, Shandong, 250100, PR, China Tel: 86-531-88364620 Fax: 86-531-88364620 
endogenous like catecholamines, dopamine, epinephrine and catecholestrogens, the others were exogenous including 3,4-Dihydroxybenzoic Aldehyde (DHBAld), 3,4-Dihydroxybenzoic Acid (DHBAc) and 3,4-Dihydroxybenzoic Alcohol (DHBAlc) (Axelrod and Tomchick, 1958; Koh et al., 1991). However, in most in vitro cases, COMT preferred DHBAc to endogenous catecholamines, dopamine and epinephrine as substrate (Pihlavisto and Reenila, 2002). A wide variety of COMT enzyme assays have also been developed such as spectrophotometric assay (Borchardt, 1974), radioassay (Gulliver and Tipton, 1978), fluorometric method (Okada et al., 1981) and so on. Of which high-performance liquid chromatography was high-sensitivity and double-quick for COMT enzyme assays (Pihlavisto and Reenila, 2002). Additionally, mass spectrometric can be used to identify the reaction products in the COMT enzyme assay (Vilbois et al., 1994). High Performance Liquid ChromatographyMass Spectrometry (HPLC-MS) therefore was employed to analyze the reaction products of purified recombinant Fc-COMT using DHBAc as substrate after termination of the enzymatic reaction.

\section{MATERIALS AND METHODS}

Chemicals: Restriction enzymes EcoRI, XhoI and Taq polymerase were purchased from TaKaRa Biotechnology Company (Dalian, China). $\mathrm{T}_{4}$ DNA ligases and DNA purification kit from Sangon Company (Shanghai, China). pET-30a(+) vector, E. coli BL21(DE3) cells and His-Bind Resin Chromatography Ni-NTA agarose were from Novagen (Germany). 4hydroxy-3-methoxybenzoic acid (vanillic acid) and 3,4Dihydroxybenzoic Acid (DHBAc) were from ACROS (Italy). S-Adenosyl-L-Methionine iodide (SAM) was from Sigma (St. Louis, MO, USA). Phosphoric acid, perchloric acid, magnesium chloride, disodium monohydrogen phosphate $\left(\mathrm{Na}_{2} \mathrm{HPO}_{4}\right)$ and sodium dihydrogen phoshate $\left(\mathrm{NaH}_{2} \mathrm{PO} 4\right)$ were of analytical grade. Acetonitrile was of HPLC grade. Water was of ultrapure reagent-grade. Standard marker proteins (phosphorylase b, $94 \mathrm{kDa}$; albumin, $67 \mathrm{kDa}$; ovalbumin, $43 \mathrm{kDa}$; carbonic anhydrase, $30 \mathrm{kDa}$; trypsin inhibitor, $20.1 \mathrm{kDa}$; $\alpha$-lactalbumin, $14.4 \mathrm{kDa}$ ) are product of Amersham Biosciences Company (Buckinghamshire, England).

Construction of Fc-COMT expression vector: Using the primer pair Met-Ex-F1 (5'TACTCAGAATTCATGTCTTCTCTGAAGAGTTAC3' and Met-Ex-R1 (5'TACTCACTCGA GGGAAGATGTGTACCTATCAG-
3'), the ORF of the Fc-COMT gene was amplified from shrimp cDNA library. Underlined bases are the restriction enzyme sites of EcoRI and XhoI PCR reaction conditions included predenaturation at $94^{\circ} \mathrm{C}$ for $3 \mathrm{~min}$, 30 cycles of $94^{\circ} \mathrm{C}$ for $30 \mathrm{sec}, 57^{\circ} \mathrm{C}$ for $45 \mathrm{sec}, 72^{\circ} \mathrm{C}$ for 1 min and an extension at $72^{\circ} \mathrm{C}$ for $10 \mathrm{~min}$. The PCR product was separated on an $1 \%$ agarose gel. A band of about 700 bp was purified by DNA purification kit.

Both the purified cDNA fragment of the Fc-COMT gene and pET-30a(+) vector were cut individually by EcoRI and XhoI The digested products were separately purified using gel purification kit and then were linked into the expression vector pET-30a(+)/FcCOMT using $\mathrm{T}_{4}$ DNA ligases. The expression vector was transformed into $E$. coli DH5 $\alpha$ cells to verify the sequence correct by restriction analysis and sequencing.

Expression and purification of recombinant FcCOMT: The obtained expression plasmid pET$30 \mathrm{a}(+) / \mathrm{FcCOMT}$ was transformed into $E$. coli BL21(DE3) cells fertilized on $\mathrm{LB}$ plate with $50 \mu \mathrm{g} \mathrm{mL}^{-1}$ kanamycin at $37^{\circ} \mathrm{C}$ overnight. Single white clone was selected to be cultured in $5 \mathrm{~mL}$ LB (50 $\mu \mathrm{g} \mathrm{mL}^{-1}$ kanamycin) liquid overnight. The overnight culture $(1 \mathrm{~mL})$ was inoculated into $100 \mathrm{~mL}$ of fresh LB medium. When bacteria grew to a density of $\mathrm{OD}_{600} \approx 0.6$, the recombinant protein was induced by addition of isopropyl $\beta$-DThiogalactopyranoside (IPTG) to a final concentration

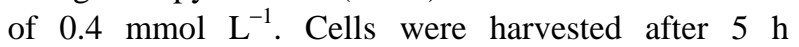
subsequently culturing and resuspended in PBS containing $0.2 \%$ Triton X-100. Following cell sonication, the cell lysate was centrifuged at 10,000 $\mathrm{g}$ for $10 \mathrm{~min}$ at $4^{\circ} \mathrm{C}$ and the supernatant and pellet were collected respectively and used for Sodium Dodecyl Sulfate Polyacrylamide Gel Electrophoresis (SDSPAGE) (Laemmli, 1974).

Following the manufacturer's instructions, the recombinant Fc-COMT was purified using His-Bind resin (Novagen, Madison, WI). The purified protein was subjected to $12.5 \%$ SDS-PAGE analysis and quantified by Bradford (1976) assay, then aliquoted and stored at $-80^{\circ} \mathrm{C}$ until its activity assay.

Activity assay of recombinant Fc-COMT using HPLC-MS: Using DHBAc as substrate, the enzymatic reaction products of Vanillic Acid (VA) and Isovanillic Acid (IVA) were detected by HPLC-MS according to methods previously described (Li et al., 2004; Reenila and Rauhala, 2009; Reenila et al., 1995).

Briefly, stock solution of standard VA and DHBAc were prepared as follows. First VA was dissolved in $100 \mu \mathrm{L}$ acetonitrile, then was adjusted to $2 \mathrm{mmol} \mathrm{L}^{-1}$ with $10 \mathrm{mmol} \mathrm{L}^{-1}$ sodium phosphate buffer (pH7.4) and 
stored at $-20^{\circ} \mathrm{C}$. VA can be diluted to $\mu \mathrm{mol} \mathrm{\textrm {L } ^ { - 1 }}$ work concentration with super-pure water. About $1 \mathrm{mmol} \mathrm{L}^{-1}$ of DHBAc can be prepared with super-pure water, stored at $-20^{\circ} \mathrm{C}$ and diluted to $200 \mu \mathrm{mol} \mathrm{L}{ }^{-1}$ with superpure water when use.

According to the literature (Reenila et al., 1995), reaction mixture $(1 \mathrm{~mL})$ contained $5 \mathrm{mmol} \mathrm{L}^{-1} \mathrm{MgCl}_{2}$, $200 \mu \mathrm{mol} \mathrm{L}^{-1}$ DHBAc, $200 \mu \mathrm{mol} \mathrm{L}{ }^{-1}$ SAM and $30 \mu \mathrm{g}$ recombinant Fc-COMT in $100 \mathrm{mmol} \mathrm{L}^{-1}$ sodium phosphate buffer (pH7.4). Sample without enzyme was run as control. After $20 \mathrm{~min}$ incubation at $37^{\circ} \mathrm{C}$ in a dark shaking water bath, $200 \mu \mathrm{mol} \mathrm{L^{-1 }}$ SAM were added and left there for another $20 \mathrm{~min}$. Reaction was stopped by the addition of $100 \mu \mathrm{L}$ of $4 \mathrm{~mol} \mathrm{~L}^{-1}$ perchloric acid and keeping in ice-bath for $10 \mathrm{~min}$. Protein precipitate was removed by centrifugation of $6000 \mathrm{~g}$ at $4^{\circ} \mathrm{C}$ for $10 \mathrm{~min}$. Supernatant was filtered by $0.22 \mu \mathrm{m}$ filter and then $20 \mu \mathrm{L}$ of reaction solution was used to HPLC analysis.

HPLC analysis was carried out according to the report (Li et al., 2004) using N2000 HPLC system that consisted of an LC-10ATUP liquid chromatography (SHIMADZU), an SPD-10AUP UV-VIS detector (SHIMADZU) and an reverse-phase $\mathrm{C}_{18}$ column $(5 \mu \mathrm{m}$, $250 \times 4.60 \mathrm{~mm}$ i.d.). The mobile phase was $15 \%$ acetonitrile with a flow rate of $1.0 \mathrm{~mL} \mathrm{~min}{ }^{-1}$, which was adjusted to $\mathrm{pH} 3.0$ with acetic acid. The column temperature was maintained at $30^{\circ} \mathrm{C}$. Peaks of chromatogram were scanned by the UV detector at $260 \mathrm{~nm}$ along with aliquots $(20 \mu \mathrm{L})$ of the samples injected by an autosampler.

HPLC-MS assay used API $4000^{\mathrm{TM}}$ LC/MS/MS System (Applied Biosystems, US) with Electrospray Inoization (ESI) in negative-inoization mode. The mass scan ranged from $\mathrm{m} / \mathrm{z}$ 50-500.

\section{RESULTS}

Expression and purification of recombinant FcCOMT: When sequencing analysis confirmed that the DNA sequence and protein sequence of pET30a $(+) / F c C O M T$ were correct, the recombinant plasmid was transformed into $E$. coli cells and recombinant Fc-COMT was induced by IPTG. As a result, the recombinant Fc-COMT band of $30 \mathrm{kDa}$ was observed by SDS-PAGE analysis. The protein reached it's the highest amount after being inducted for $4 \mathrm{~h}$ (Fig. 1). Also, the recombinant Fc-COMT existed in the supernatant of $E$. coli lysate in soluble form and easily purified by the His-Bind resin chromatography (Fig. 2).

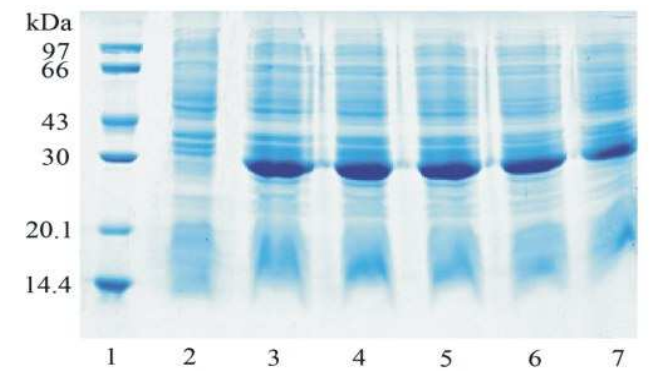

Fig. 1: SDS-PAGE analysis and Coomassie Blue staining of bacterial protein extracts induced by IPTG. Lane 1 is molecular mass markers. Lane 2 is crude protein extracts of bacteria of noninduction; Crude extracts of bacteria cells induced for 5, 4, 3, 2 and $1 \mathrm{~h}$ from lane 3 to lane 7 (protein loading is $40 \mu \mathrm{g} \mathrm{well}^{-1}, 12.5 \%$ gel)

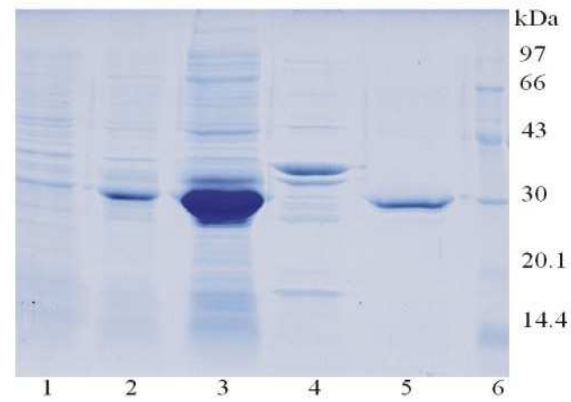

Fig. 2:SDS-PAGE analysis and Coomassie Blue staining of recombinant protein purified. Lane 1: Crude extract of uninduced bacteria cells; Lane 2: Crude extract of induced bacteria cells. Soluble and insoluble protein fraction of bacteria cells induced for $4 \mathrm{~h}$ in Lane 3 and Lane 4 respectively. Recombinant protein purified by His•Bind affinity column in Lane 5. Lane 6 for molecular mass markers (protein loading is $15 \mu \mathrm{g}$ well $^{-1}, 12.5 \%$ gel)

Activity assay of recombinant Fc-COMT: Under HPLC analysis, VA of $0.4 \mu \mathrm{mol} \mathrm{L}^{-1}$ was underdetectable, but $16 \mu \mathrm{mol} \mathrm{L} \mathrm{L}^{-1} \mathrm{VA}$ gave a single peak of chromatogram that had $10 \mathrm{mv}$ height and an retention time of $9.4 \mathrm{~min}$ (Fig. 3a), also, the mixture of $200 \mu \mathrm{mol} \mathrm{L} \mathrm{L}^{-1}$ DHBAc and $10 \mu \mathrm{mol} \mathrm{L} \mathrm{L}^{-1} \mathrm{VA}$ showed no interfered peak of chromatogram, in which the VA peak had the same retention time to that VA peak in Fig. $3 \mathrm{a}$ and the retention time of the DHBAc peak was $5.2 \mathrm{~min}$ (Fig. 3b). The chromatogram of reaction mixture as control containing $200 \mu \mathrm{mol} \mathrm{L}^{-1}$ DHBAc and $200 \mu \mathrm{mol} \mathrm{L}{ }^{-1}$ SAM without recombinant Fc-COMT gave several peaks, of which the height of DHBAc peak was $130 \mathrm{mv}$. 


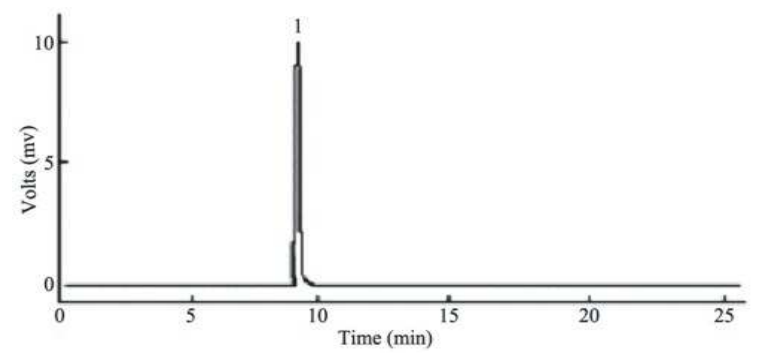

(a)

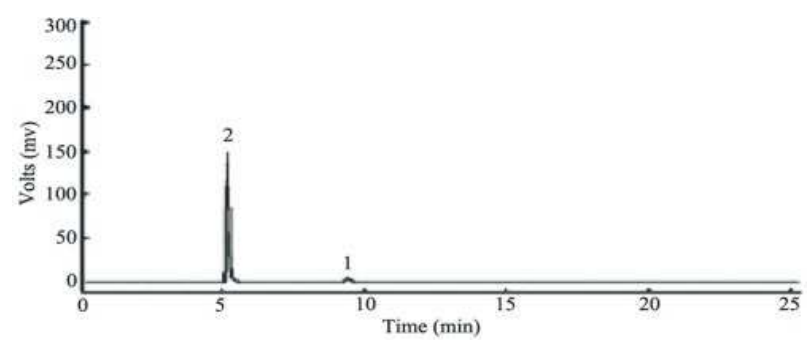

(b)

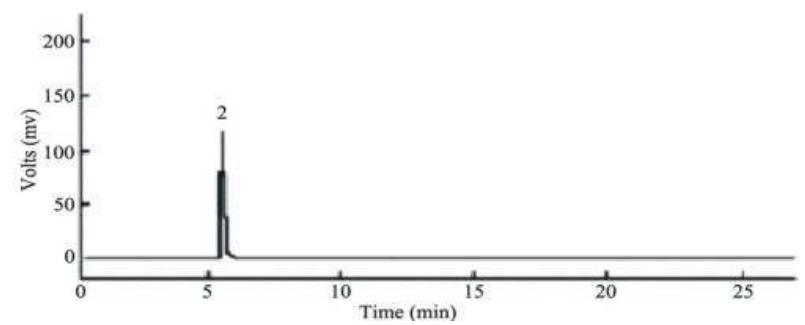

(c)

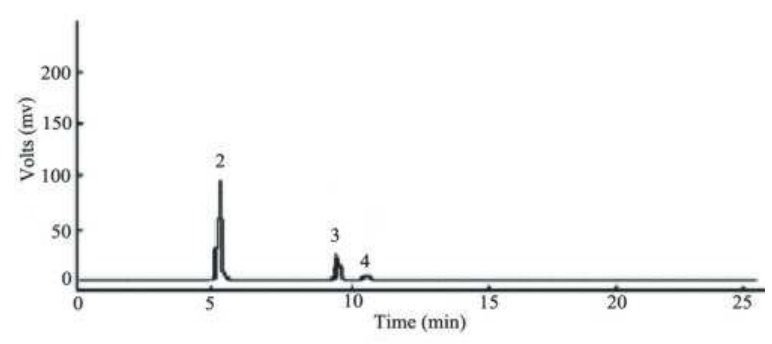

(d)

Fig. 3: The activity assay of recombinant Fc-COMT by HPLC. (a) Chromatogram of standard VA, whose concentration is $16 \mu \mathrm{m}$. (b) Chromatogram of standard VA of $10 \mu \mathrm{m}$ and $200 \mu \mathrm{m}$ DHBAc. (c) Chromatogram of the control containing $200 \mu \mathrm{M}$ DHBAc and $200 \mu \mathrm{M}$ SAM without enzyme. (d) Chromatogram of reaction solution with $30 \mu \mathrm{g}$ recombinant FcCOMT except for $200 \mu \mathrm{m}$ DHBAc and $200 \mu \mathrm{m}$ SAM. Peak 1 and peak 2 stand for standard VA and DHBAc respectively. Peak 3 and Peak 4 stand for two methyl products of DHBAc. Injection volume was $20 \mu \mathrm{L}$. Reaction mixture were scanned by UV detector

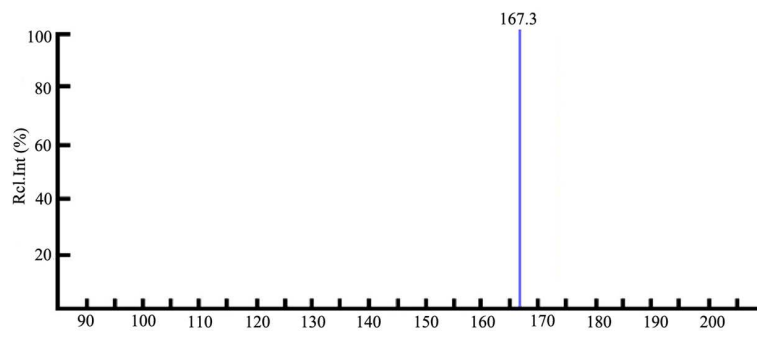

Fig. 4: Mass spectrum of peak 3 in Fig. 3

No peak was observed in the retention time from 9.417 min (Fig. 3c). However, as compared with the control, two kinds of new peaks appeared in the chromatogram of reaction mixture containing $30 \mu \mathrm{g}$ recombinant Fc-COMT, the main new-peak was at retention time of $9.4 \mathrm{~min}$ and had $20 \mathrm{mv}$ peak height and the smaller at $10.4 \mathrm{~min}$ (height $2.3 \mathrm{mv}$ ). In addition, the height of DHBAc peak decreased to 96 mv (Fig. 3d).

Using HPLC-MS to scan the reaction mixture, the mass spectra of the main new-peak with retention time of $9.4 \mathrm{~min}$ in HPLC analysis was $\mathrm{m} / \mathrm{z} 167.3$ of its [M$\mathrm{H}]^{-}$peak (Fig. 4). Then the main new-peak should stand for a kind of substance with molecular weight of 168.3.

\section{DISCUSSION}

According to previous report (Li et al., 2006), the Fc-COMT gene contained a single Open Reading Frame (ORF) of 666 bp encoding a protein of 221 amino acids with the predicted molecular weight of $24.57 \mathrm{kDa}$. When the ORF of the Fc-COMT gene was constructed into prokaryotic expression vector pET30a (+), the recombinant Fc-COMT will have a His tag of about $5 \mathrm{kDa}$ at its $\mathrm{N}$ terminal. So, It can be speculated that the $30 \mathrm{kDa}$ induced protein should be the fusion of the Fc-COMT and the His tag in Fig. 1.

Because COMT can catalyze the transferring of methyl group from SAM to the 3' hydroxyl or 4' hydroxyl group of benzyl ring of DHBAc, two types of methyl products of 4-hydroxy-3-methoxybenzoic acid (VA) and 3-hydroxy-4-Methoxybenzoic Acid (IVA) should be formed respectively (Tuomainen et al., 1996). Here, the master maps of Fig. 3 (Fig. 5) have revealed either standard VA or substrate DHBAc all gave a single peak of chromatogram and their retention times were 9.4 and 5.2 min respectively (Fig. 5a, 5b). This indicated the standard VA and the substrate DHBAc all had high purity. In the control chromatogram (Fig. 5c) there was no product peak from the retention time of 9.4-17 $\mathrm{min}$. 
Am. J. Biochem. \& Biotech., 6 (3): 148-154, 2010

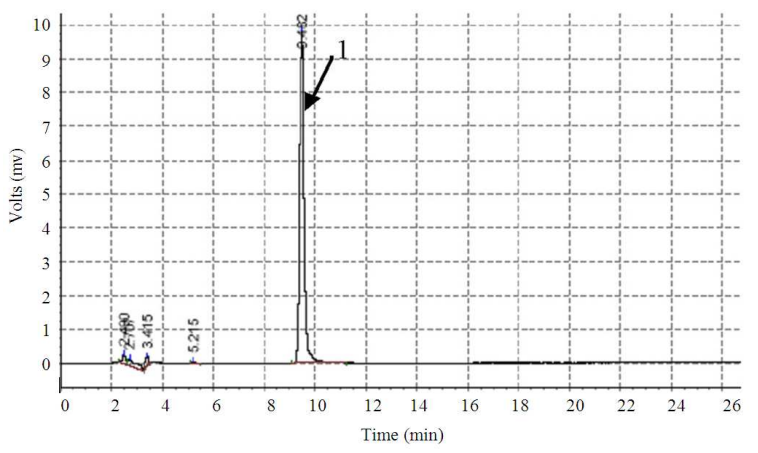

(a)

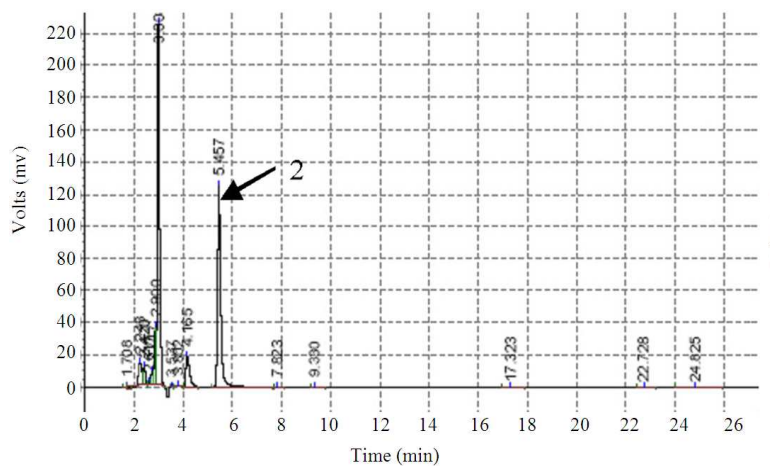

(c)

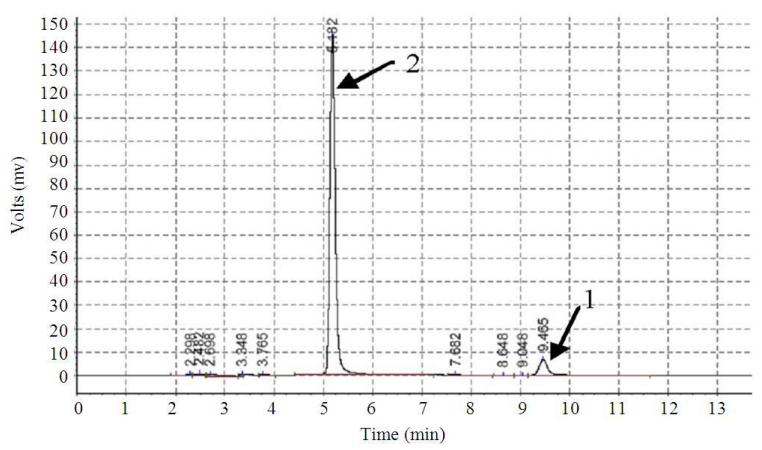

(b)

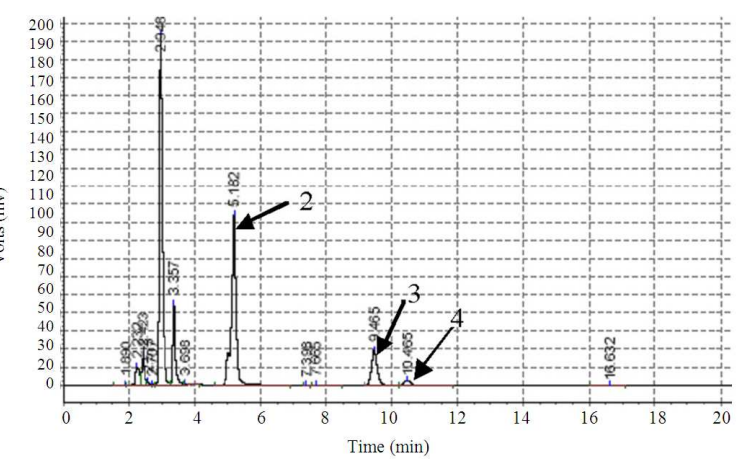

(d)

Fig. 5: The activity assay of recombinant Fc-COMT by HPLC. (a) Chromatogram of standard VA, whose concentration is $16 \mu \mathrm{m}$; (b) Chromatogram of standard VA of $10 \mu \mathrm{M}$ and $200 \mu \mathrm{m}$ DHBAc; (c) Chromatogram of the control containing $200 \mu \mathrm{m}$ DHBAc and $200 \mu \mathrm{m}$ SAM without enzyme; (d) Chromatogram of reaction solution with $30 \mu \mathrm{g}$ recombinant protein except for $200 \mu \mathrm{m}$ DHBAc and $200 \mu \mathrm{M}$ SAM. Peak 1 and peak 2 stand for standard VA and DHBAc respectively. Peak 3 and peak 4 stand for two methyl products of DHBAc. Injection volume was $20 \mu \mathrm{L}$. Reaction mixture were scanned by UV

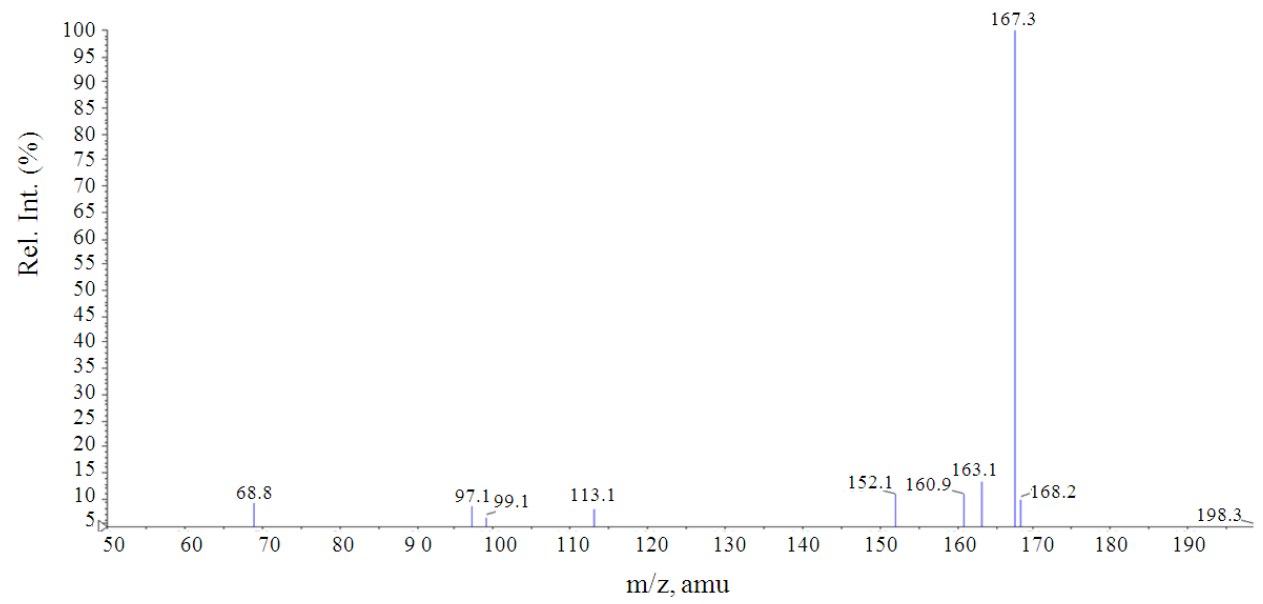

Fig. 6: Mass spectrum of peak 3 in Fig. 5d

While in the reaction chromatogram two of new peaks, marked 3 and 4, appeared at the retention time of $9.4 \mathrm{~min}$ and 10.4 min respectively and the height of DHBAc peak had declined by $34 \mathrm{mv}$ (Fig. $5 \mathrm{~d}$ ). So it was supposed that 
the DHBAc had been methylated by the recombinant FcCOMT and the two of new peaks may be product-peaks.

By comparing, the Peak 3 was bigger than Peak 4 and had the same retention time as standard VA, in addition, when VA was added to the reaction mixture, the big peak became higher and no additional peak was observed (data not shown). The big peak may be stand for a kind of product, VA. HPLC-MS further validated the product had a molecular weight of 168.3 that was the same as VA (Fig. 6). Taken together, the peak 3 should stand for the reaction product VA, while that peak 4 with retention time $10.4 \mathrm{~min}$ (height $2.3 \mathrm{mv}$ ) should stand for the second product of IVA. Since the methyl products of DHBAc, VA and IVA, have been detected in the reaction mixtures with the recombinant Fc-COMT by HPLC-MS, the recombinant Fc-COMT has COMT activity.

\section{CONCLUSION}

This research details the expression and purification as well as activity assay of recombinant FcCOMT. The recombinant Fc-COMT existed in the supernatant of $E$. coli lysate in soluble form and was easily purified by the His-Bind resin chromatography. Two types of methyl products of DHBAc, VA and IVA, were detected in the enzymatic reaction mixtures with recombinant Fc-COMT by HPLC-MS. Therefore, we can conclude the recombinant Fc-COMT has been successfully expressed and purified from E. coli strain and the recombinant Fc-COMT has catalytic activity of transferring methyl group from SAM to the 3' hydroxyl or 4' hydroxyl group of benzyl ring of DHBAc.

\section{ACKNOWLEDGEMENT}

This study was financially supported by the National Natural Science Foundation of China (No. 30770282, 30972236) and the National High Technology Research and Development Program of China (863 Program) (No. 2007AA09Z425) to JXW.

\section{REFERENCES}

Axelrod, J. and R. Tomchick, 1958. Enzymatic Omethylation of epinephrine and other catechols. J. Biol. Chem., 233: 702-705. PMID: 13575440

Bertocci, B., V. Miggiano, M. da Prada, Z. Dembic and H.W. Lahm et al., 1991. Human catechol-Omethyltransferase: Cloning and expression of the membrane-associated form. Proc. Natl. Acad. Sci. USA., 88: 1416-1420. PMID: 1847521
Bonifacio, M.J., M. Archer, M.L. Rodrigues, P.M. Matias and D.A. Learmonth et al., 2002. Kinetics and crystal structure of catechol-O-methyltransferase complex with co-substrate and a novel inhibitor with potential therapeutic application. Mol. Pharmacol., 62: 795-805. PMID: 12237326

Borchardt, R.T., 1974. A rapid spectrophotometric assay for catechol-O-methyltransferase. Anal. Biochem., 58: 382-389. PMID: 4827387

Bradford, M.M., 1976. A rapid and sensitive method for the quantization of microgram quantities of protein utilizing the principle of protein-dye binding. Anal. Biochem., 72: 248-254. PMID: 942051

Chen, J., B.K. Lipska, N. Halim, Q.D. Ma and M. Matsumoto et al., 2003. Functional analysis of genetic variation in Catechol-O-Methyltransferase (COMT): Effects on mRNA, protein and enzyme activity in postmortem human brain. Am. J. Hum. Genet., 75: 807-821. PMID: 15457404

Cheng, T.C., S.T. Chen, C.S. Huang, Y.P. Fu and J.C. Yu et al., 2005. Breast cancer risk associated with genotype polymorphism of the catechol estrogen-metabolizing genes: A multigenic study on cancer susceptibility. Int. J. Cancer, 113: 345-353. PMID: 15455371

Guldberg, H.C. and C.A. Marsden, 1975. Catechol-Omethyl transferase: Pharmacological aspects and physiological role. Pharmacol. Rev., 27: 135-206. PMID: 1103160

Gulliver, P.A. and K.F. Tipton, 1978. Direct extraction radioassay for catechol-Q-methyl-transferase activity. Biochem. Pharmacol., 27: 773-775. PMID: 656116

Karayiorgou, M., J.A. Gogos, B.L. Galke, P.S. Wolyniec and G. Nestadt et al., 1998. Identification of sequence variants and analysis of the role of the catechol-O-methyl-transferase gene in schizophrenia susceptibility. Biol. Psychiatry, 43: 425-431. PMID: 9532347

Koh, S., K. Urayama, S. Kawai and Y. Takayama, 1991. Application of a metal capillary column in gas chromatographic determination of catecholo-methyltransferase activity. J. Chromatogr., 549: 434-439. PMID: 1770086

Laemmli, U.K., 1970. Cleavage of structural proteins during the assembly of the head of bacteriophage $\mathrm{T}_{4}$. Nature, 227: 680-685. PMID: 5432063

Li, D.X., X.J. Du, X.F. Zhao and J.X. Wang, 2006. Cloning and expression analysis of an OMethyltransferase (OMT) gene from Chinese shrimp, Fenneropenaeus chinensis. Fish Shellfish Immunol., 21: 284-292. PMID: 16530427 
Li, K., X. Chen, Y. Jia and K. Bi, 2004. Reverse-phase HPLC determination and pharmacokinetic study of vanillic acid in the plasma of rats treated with the traditional Chinese medicinal preparation $\mathrm{Di}-\mathrm{Gu}-\mathrm{Pi}$ decoction. Yakugaku Zasshi, 124: 465-468. PMID: 15235230

Mannisto, P.T., I. Ulmanen, K. Lundstrom, J. Taskinen and J. Tenhunen et al., 1992. Characteristics of Catechol O-Methyl-transferase (COMT) and properties of selective COMT inhibitors. Prog. Drug. Res., 39: 291-350. PMID: 1475365

Matsumoto, M., C.S. Weickert, M. Akil, B.K. Lipska and T.M. Hyde et al., 2003. Catechol Omethyltransferase mRNA expression in human and rat brain: Evidence for a role in cortical neuronal function. Neuroscience, 116: 127-137. PMID: 12535946

Okada, Y., K. Zaitsu, K. Ohtsubo, H. Nohta and Y. Ohkura, 1981. Fluorimetric assay for catecholO-methyltransferase. Chem. Pharm. Bull., 29: 1670-1673. PMID: 7296717

Pihlavisto, P. and I. Reenila, 2002. Separation methods for catechol O-methyltransferase activity assay: Physiological and pathophysiological relevance. J. Chromatogr. B. Anal. Technol. Biomed. Life Sci., 781: 359-372. PMID: 12450669

Reenila, I. and P. Rauhala, 2009. Simultaneous analysis of catechol-O-methyltransferase activity, Sadenosylhomocysteine and adenosine. Biomed. Chromatogr., 24: 294-300. PMID: 19629963
Reenila, I., P. Tuomainen and P.T. Mannisto, 1995. Improved assay of reaction products to quantitate catechol-O-methyltransferase activity by highperformance liquid chromatography with electrochemical detection. J. Chromatogr. B. Biomed. Sci. Appli., 663: 137-142. PMID: 7704200

Schrag, A., 2005. Entacapone in the treatment of Parkinson's disease. Lancet Neurol., 4: 366-370. PMID: 15907741

Tilgmann, C. and I. Ulmanen, 1996. Purification methods of mammalian catechol-Omethyltransferases. J. Chromatogr. B. Biomed. Appli., 684: 147-161. PMID: 8906471

Tuomainen, P., I. Reenila and P.T. Mannisto, 1996. Validation of assay of catechol-Omethyltransferase activity in human erythrocytes. J. Pharm. Biomed. Anal., 14: 515-523. PMID: 8738181

Vilbois, F., P. Caspers, M. da Prada, G. Lang and C. Karrern et al., 1994. Mass spectrometric analysis of human soluble catechol Omethyltransferase expressed in Escherichia coli. Identification of a product of ribosomal frameshifting and of reactive cysteines involved in S-adenosyl-L-methionine binding. Eur. J. Biochem., 222: 377-386. PMID: 8020475 